\title{
Effect of Listening to Preferred Music on Intensity of Pain and Physiologic Parameters in Patients Undergoing Coronary Artery Bypass Grafting Surgery
}

Mostafa Shokati Ahmadabad ${ }^{1} \mathrm{PhD}$, Ali Changizi ${ }^{2} \mathrm{MD}$, Shahram Ghorbani ${ }^{1}$ MSc, Mitra Azarasa ${ }^{3}$ MD, Hossein Rafiei $^{1}$ MSc

${ }^{I}$ Department of Critical Care, School of Nursing and Midwifery, Qazvin University of Medical Science, Qazvin, Iran.

${ }^{2}$ Department of Cardiac Surgery, School of Medicine, Qazvin University of Medical Science, Qazvin, Iran.

${ }^{3}$ Department of Cardiac Anesthesia, School of Medicine, Qazvin University of Medical Science, Qazvin, Iran. Correspondence to: Mostafa Shokati Ahmadabad.Email: msn_sho@yahoo.com

\begin{abstract}
:
Background and Aim: Pain is common patient complaint after Coronary Artery Bypass Grafting (CABG) surgery. In present study, we examined the effect of listening to preferred music on intensity of pain and physiologic parameters in patients undergoing CABG surgery.

Methods: In a randomized controlled clinical trial, 50 patients who were under CABG surgery were randomly assigned to group " $A$ " (control group) or group " $B$ " (intervention group). Patients in group " $A$ " received usual care after surgery. In addition to usual care, patients in group " $B$ " listened their preferred music (music played by MP4 player with special headphones for 30 minutes two time per day (10 am and $17 \mathrm{pm})$ ). Patients' pain and physiologic parameters (heart rate, respiratory rate, diastolic and systolic blood pressure) were measured with using Numerical Rating Scale (NRS) and standard apparatus immediately before and 30 minute after intervention.

Results: The mean score of pain intensity before and after intervention in patients in group " $B$ " was $4.18 \pm$ 2.68 and $3.13 \pm 2.55$ respectively $(p<0.05)$. The mean score of pain intensity before and after intervention in patients in group " $A$ " was $5.16 \pm 1.37$ and $5.20 \pm 1.38$ respectively $(p>0.05)$. Among physiologic parameters, heart rate and respiratory rate decreased significantly in patients in group " $B$ " $(P>0.05)$.

Conclusion: Music is should be considered by clinicians as a non pharmacological, non invasive, simple, cheap, safe, and effective method for pain management after CABG surgery. Music also has not negative effect of patient's physiologic parameters.
\end{abstract}

Keywords: Pain, vital signs, cardiac surgery, music, non pharmacological methods

\section{Introduction}

Surgical revascularization, also known as Coronary Artery Bypass Grafting (CABG) is common surgical procedures in which an arterial or venous vessel from another part of the body is grafted below the occluded coronary artery so that blood can bypass the blockage $[1,2,3]$. Acute pain after cardiac surgery is very common $[4,5,6,7,8,9]$. Most previous studies showed that cardiac surgery patients experienced moderate to severe pain $[3,5]$. Results of one study showed that thirty-eight per cent of patients experienced some level of pain after cardiac surgery [5].

Patient's pain could be treated with pharmacologic and non-pharmacologic methods. Nonpharmacologic therapies for pain relief have become increasingly popular among researchers in recent years. At now, several non-pharmacologic therapies have been proposed to relieve post cardiac surgery pain including muscle relaxation, cold gel pack, music therapy, massages therapy, Transcutaneous Electrical Nerve Stimulation (TENS), electroacupuncture and prayer $[10,11,12,13,14,15,16]$. In one study in this regards in 2009, Sadeghi et al., examined the effect of foot reflex massage on postoperative pain in patients after CABG. They applied 10-minute right foot massage in desired location twice a day with 6 hours intervals for 2 consecutive days. Results of Sadeghi et al., study showed that foot reflex massage decreased pain intensity in patients after CABG significantly [17]. In other study in this regards, Solak et al., compared continuous and intermittent TENS in post operative pain management in patients with CABG. They allocated 100 patients in 4 groups: 1) continuous TENS and pharmacologic analgesia, 2) intermittent TENS and pharmacologic analgesia, 3) placebo TENS and pharmacologic analgesia, and 4) pharmacologic analgesia alone. Results of Solak et al., study showed that both continuous and intermittent TENS are effective with similar effect in decreasing CABG patients' pain after surgery [14]. In another study with pretest-posttest design in 2012, Özer et al., examined the effect of music on postoperative pain and physiologic parameters of patients after open heart surgery. Results of Özer et al., study 
showed that use of music for patients after open heart surgery increased oxygen saturation and decreased pain level in this group of patients significantly [10].

Although, several non-pharmacologic therapies have been proposed to relieve post cardiac surgery pain, however in some field such as music therapy there are few studies. In present study, we examined the effect of listening to preferred music on severity of pain and physiologic parameters in patients undergoing CABG surgery.

\section{Methods}

This study is a randomized controlled clinical trial conducted from January 2014 to July 2014. Samples were 50 patients who have CABG and were hospitalized in cardiac intensive care unit of a governmental hospital in Qazvin, Iran. This study has received permissions from medical ethics' board of the Qazvin University of Medical Sciences. This study also registered in Iranian Registry of Clinical Trials. Each patient received oral information about study aim and asked to fill in a written consent form. Inclusions criteria of the study were: men and women who have non emergency CABG surgery, age between 35 to 80 years, reading and writing ability and first time open heart surgery. Addicted patient (both drug and alcohol), patients who needs more than one day to mechanical ventilation after surgery, patients with history of depression, chronic pain, delirium and hearing impairment were excluded from study.

According to the sample size formula, the sample size determined 50. Eligible patients whom were found at the time of cardiac unit admission, were randomly assigned to group "A" (control group) or group "B" (intervention group) by the supervisor of the cardiac unit, who chose the next serially numbered sealed opaque envelope containing a simple 1:1 randomization sequence. Patients in group "A", received usual care after surgery. In addition to usual care, patients in group "B" listened preferred music (music played by MP4 player with special headphones for 30 minutes two time per day (10 am and $17 \mathrm{pm})$. All music pieces were selected by patients under supervision of a musician considering the cultural conditions of the society and with a rate of 6080 beats per minute and a general absence of strong rhythms or percussion. Changing the music volume was in the control of the patient.

First a check list was designed to obtain demographics information and physiologic parameters. Patients' physiologic parameters (heart rate, respiratory rate, diastolic and systolic blood pressure) were measured with using standard apparatus by researcher (ShGh) immediately before and 30 minute after intervention. Patients pain were measured by researcher (ShGh) who have sufficient knowledge in this regards with using $0-10$ point Numerical Rating Scale (NRS). Patient's pain was measured immediately before and 30 minute after intervention in patients in both group. The data was analysed using the Statistical Package for the Social Sciences (SPSS 18). A P-value of less than 0.05 was considered as statistically significant. Descriptive statistics (expressed as mean and standard deviation) and independent $\mathrm{T}$ - test for comparing the means of normally distributed independent-samples were used.

\section{Results}

Of 25 patients of group "B", two patients withdrew due to their own request. Of the 48 patients, 33 were men. The mean age of all patients was $57.4 \pm 10.3$ years. The demographic characteristics including age, sex, weight, marital status and level of education in time of cardiac unit admission were similar in patients in group "A" and "B" (Table 1).

\section{Pain score}

There was no significant difference regarding baseline pain intensity among patients in group " $A$ " and "B". The mean score of pain intensity before and after intervention in patients in group "B" was $4.18 \pm 2.68$ and $3.13 \pm 2.55$ respectively. According to results of independent $t$ test this difference was statistically significant $(\mathrm{p}<0.05)$. The mean score of pain intensity before and after intervention in patients in group " $\mathrm{A}$ " was $5.16 \pm$ 1.37 and $5.20 \pm 1.38$ respectively. Although mean score of patients pain were increased, however this difference was not statistically significant $(\mathrm{p}>0.05)$.

\section{Physiologic parameters}

Information about patient's physiologic parameters before and after intervention in patients in group "A" and "B" showed in table two.

\section{Discussion}

In addition to medication therapy, non pharmacological methods, such as music, can be implemented to alleviate pain after surgery [18]. Present study aimed to examine the effect of music listening on severity of pain and vital signs in patients undergoing CABG surgery. According to finding of present study listening to preferred music have positive effect in patients pain intensity. 
Effect of Listening to Preferred Music on Intensity of Pain and Physiologic Parameters in Patients..

Pain is common patient complaint after surgery and produces several responses such as autonomic, psychological, immunological and behavioral [19]. Surgery on the chest and heart involves several painsensitive structures [10]. If patients postoperative pain not well managed, complications such as pneumonia, myocardial ischemia, cardiac arrhythmias, increase rate of delirium, surgical site wound infection and chronic pain may occur $[2,20]$. Pains also delayed patient's functional recovery post-CABG surgery and decrease overall quality of life [21, 22]. Although findings from previous studies showed a high prevalence of pain among adults after cardiac surgery [8, 10], however pain after cardiac surgery remains poorly documented [3]. Music as a non-pharmacologic therapies method for pain relief after CABG surgery investigated in few studies. Similar to finding of present study, most previous study in this regards showed similar finding. In one study in 2012, Jafari et al., examined the effects of listening to music on patients pain level after open heart surgery. They allocated 60 patients in two groups. Patients in the intervention group listened to preferred music for 30 minutes and patients in the control group did not listen to music. They used NRS to measured patients pain before, immediately, 30 minutes and one hour after the intervention. Results of Jafari et al., showed that patients pain decreased significantly after listening to music [23]. In another study, Mirbagher et al., examined effect of music on postoperative pain in patients under open heart surgery. Similar to finding of present study, Mirbagher et al., reported that music significantly decreased postoperative pain after open heart surgery [24]. In other study in 2006, Sendelbach et al., examined the effects of music therapy on physiological and psychological outcomes for patients undergoing cardiac surgery. They reported that music have significant effect in reducing pain and anxiety in this group of patients after surgery [25]. Although result of present study and other previous studies showed that music have a positive effect on patient's pain after cardiac surgery however researchers and clinicians should consider patients' culture, music type, music time and time of day that music played. Because these factors affect music role in decreasing pain.

Results of present study also showed that listening to preferred music after CABG surgery have positive effect on patients vital signs. Previous study in this regards also is limited. In one study in 1997, Byers \& Smyth examined the effect of listening to music on noise annoyance, heart rate and blood pressure in cardiac surgery patients in the first day after surgery. Results of Byers \& Smyth study showed that listening to music after cardiac surgery decrease noise annoyance, heart rate and blood pressure [27]. In other study Özer et al., in 2013 examined the effect of listening to personal choice of music on the physiologic parameters (blood pressure, heart rate, oxygen saturation, and respiratory rate) in 87 patients who have undergone open heart surgery. Results of Özer et al., study showed that listening to music increased patients oxygen saturation level significantly. No difference between the groups in the other physiologic parameters was reported by Özer et al [10]. In other study Sendelbach et al., reported that music have not negative effect on physiological parameter of patients after cardiac surgery [25].

\section{Conclusion}

Music is a non pharmacological, non invasive, simple, cheap, safe, and effective method for pain management after CABG surgery. Music also has positive effect on patients vital signs such as heart rate, blood pressure and respiratory rate. Further study recommended investigating the long-term effects of listening to music in $\mathrm{CABG}$ surgery patients.

\section{Acknowledgment}

We would like to thanks all patients who accept to participant in present study.

\section{Declaration of interest}

No

\section{References}

[1] Jones J, Fix B. Critical Care Notes. Philadelphia, Davis Company, 2009, 42

[2] Hardin SR, Kaplow R. Cardiac Surgery Essential for Critical Care Nursing. Sudbury, Jones and Bartlett Publishers, 2010;27-300.

[3] Eisenberg E, Pultorak Y, Pud D, Bar-El Y. Prevalence and characteristics of post coronary artery bypass graft surgery pain (PCP). Pain. 2001;92(1-2):11-7.

[4] Babaee T, sadeghi R, Bakhshandeh H. The effect of pre-operative education on post-operative pain perception in patient undergoing Coronary Artery Bypass Graft. Cardiovascular Nursing Journal. 2014; 3 (2) :40-47.

[5] Bjørnnes AK, Rustøen T, Lie I, Watt-Watson J, Leegaard M. Pain characteristics and analgesic intake before and following cardiac surgery. Eur J Cardiovasc Nurs. 2014 Sep 5. pii: 1474515114550441.

[6] Aslan FE, Badir A, Arli SK, Cakmakci H. Patients' experience of pain after cardiac surgery. Contemp Nurse. 2009;34(1):48-54

[7] Parry M, Watt-Watson J, Hodnett E, Tranmer J, Dennis CL, Brooks D. Pain experiences of men and women after coronary artery bypass graft surgery. J Cardiovasc Nurs. $2010 ; 25(3)$ :E9-E15.

[8] Martorella G, Gélinas C, Purden M. Acceptability of a web-based and tailored intervention for the self-management of pain after cardiac surgery: the perception of women and men. JMIR Res Protoc. 2014;3(4):e63.

[9] Koranyi S, Barth J, Trelle S, Strauss BM, Rosendahl J. Psychological interventions for acute pain after open heart surgery. Cochrane Database Syst Rev. 2014; 26(5):CD009984. 
[10] Özer N, Karaman Özlü Z, Arslan S, Günes N. Effect of music on postoperative pain and physiologic parameters of patients after open heart surgery. Pain Manag Nurs. 2013;14(1):20-8.

[11] Khalkhali H, Tanha ZE, Feizi A, Ardabili SS. Effect of applying cold gel pack on the pain associated with deep breathing and coughing after open heart surgery. Iran J Nurs Midwifery Res. 2014;19(6):545-9.

[12] Zimmerman L1, Nieveen J, Barnason S, Schmaderer M. The effects of music interventions on postoperative pain and sleep in coronary artery bypass graft (CABG) patients. Sch Inq Nurs Pract. 1996;10(2):153-70; discussion 171-4.

[13] Najafi SS, Rast F, Momennasab M, Ghazinoor M, Dehghanrad F, Mousavizadeh SA. The effect of massage therapy by patients' companions on severity of pain in the patients undergoing post coronary artery bypass graft surgery: a single-blind randomized clinical trial. Int J Community Based Nurs Midwifery. 2014;2(3):128-35.

[14] Solac O, Emmiler M, Ela Y, Dunder U, Kocoiullari CU, Eren N, Gokce IY, Cekirdekci A, Kavuncu V. Comparison of continuous and intermittent transcutaneous electrical nerve stimulation in post operative pain management after coronary artery bypass grafting: a randomized, placebo-controlled prospective study. Heart Surgery Forum. 2009; 12(5):E266-71.

[15] Colak MC, Kavakl A, Kılınç A, Rahman A. Postoperative pain and respiratory function in patients treated with electroacupuncture following coronary surgery. Neurosciences 2010;15 (1): 7-10.

[16] Nasiri M, Fayazi S, Ghaderi M, Naseri M, Adarvishi S. The effect of reciting the word "allah" on pain severity after coronary artery bypass graft surgery: a randomized clinical trial study in Iran. Anesth Pain Med. 2014;4(5):e23149.

[17] Sadeghi Shermeh M, Bozorgzad P, Ghafourian A, Ebadi A, Razmjoei N, Afzali M, Azizi A. Effect of foot reflex massage on sternotomy pain after coronary artery bypass graft surgery. Iranian Journal of Critical Care Nursing. 2009; 2(2): 51-54.

[18] Kankkunen P, Vaajoki A. Songs for silent suffering: could music help with postsurgical pain? Pain Manag. 2014;4(1):1-3.

[19] Dunn K. Music and the reduction of post-operative pain. Nurs Stand. 2004;18(36):33-9.

[20] Mazzeffi M, Khelemsky Y. Poststernotomy pain: a clinical review. J Cardiothorac Vasc Anesth. 2011;25(6):1163-78.

[21] Glowacki D. Effective pain management and improvements in patients' outcomes and satisfaction. Crit Care Nurse. 2015;35(3):3341.

[22] Morone NE, Weiner DK, Belnap BH, Karp JF, Mazumdar S, Houck PR, He F, Rollman BL. The impact of pain and depression on recovery after coronary artery bypass grafting. Psychosom Med. 2010;72(7):620-5.

[23] Jafari H, Emami Zeydi A, Khani S, Esmaeili R, Soleimani A. The effects of listening to preferred music on pain intensity after open heart surgery. Iran J Nurs Midwifery Res. 2012 17(1):1-6.

[24] Mirbagher Ajorpaz N, Mohammadi A, Najaran H, Khazaei S. Effect of music on postoperative pain in patients under open heart surgery. Nurs Midwifery Stud. 2014;3(3):e20213. Epub 2014 Sep 20.

[25] Sendelbach SE, Halm MA, Doran KA, Miller EH, Gaillard P. Effects of music therapy on physiological and psychological outcomes for patients undergoing cardiac surgery. Journal of Cardiovascular Nursing. 2006;21(3):194-200.

[26] Byers JF, Smyth KA. Effect of music intervention on noise annoyance, heart rate, and blood pressure in cardiac surgery patients. Am J Crit Care. 1997;6(3):183-91.

Tables

Table 1: Patients demographics characteristics in both groups

\begin{tabular}{|c|c|c|c|c|}
\hline \multicolumn{2}{|l|}{ Item } & Group "A" & Group "B" & P value \\
\hline \multicolumn{2}{|l|}{ Age } & $59.3 \pm 11.8$ & $55.5 \pm 9.5$ & $P=0.23$ \\
\hline \multicolumn{2}{|l|}{ Weigh (kg) } & $72.1 \pm 8.1$ & $78.3 \pm 12.8$ & $P=0.05$ \\
\hline \multirow[t]{2}{*}{ Sex } & Men & 16 & 17 & \multirow[t]{2}{*}{$P=0.49$} \\
\hline & Women & 9 & 6 & \\
\hline \multirow[t]{2}{*}{ Marital status } & Married & 25 & 20 & \multirow[b]{2}{*}{$P=0.10$} \\
\hline & Single & 0 & 3 & \\
\hline \multirow[t]{4}{*}{ Education level } & Illiterate & 3 & 1 & \multirow{4}{*}{$P=0.07$} \\
\hline & Primary school & 10 & 13 & \\
\hline & High school & 9 & 7 & \\
\hline & Graduate & 3 & 2 & \\
\hline \multirow[t]{2}{*}{ Diabetic } & Yes & 10 & 9 & \multirow[t]{2}{*}{$P=0.95$} \\
\hline & No & 15 & 14 & \\
\hline
\end{tabular}

Table 2: Physiologic parameters before and after intervention in patients in both groups

\begin{tabular}{|l|l|l|l|l|l|l|}
\hline Parameter & \multicolumn{2}{|l|}{ Group "A" } & \multirow{2}{*}{$P$ value } & \multicolumn{2}{l|}{ Group “B” } & \multirow{2}{*}{$P$ value } \\
\cline { 2 - 3 } \cline { 5 - 7 } & Before & After & & Before & After & \\
\hline Systolic blood pressure & $111.1 \pm 20.7$ & $110.9 \pm 17.9$ & $P=0.87$ & $114.3 \pm 14.5$ & $110.5 \pm 13.3$ & $P=0.09$ \\
\hline Diastolic blood pressure & $63.3 \pm 14.6$ & $63.3 \pm 12.1$ & $P=0.90$ & $74.2 \pm 11.1$ & $72.3 \pm 10.7$ & $P=0.19$ \\
\hline Heart rate & $93.2 \pm 8.1$ & $93.4 \pm 8.8$ & $P=0.81$ & $91.7 \pm 9.2$ & $89.4 \pm 10.3$ & $P=0.01$ \\
\hline Respiratory rate & $23.8 \pm 3.8$ & $23.6 \pm 4.1$ & $P=0.28$ & $24.4 \pm 5.7$ & $21.5 \pm 4.7$ & $P=0.01$ \\
\hline
\end{tabular}

